\title{
A SIMETRIA QUE NÃO É PRINCÍPIO: ANÁLISE E CRÍTICA DO PRINCÍPIO DA SIMETRIA DE ACORDO COM O SENTIDO DE FEDERALISMO NO BRASIL
}

\section{THE SYMMETRY THAT IS NOT A PRINCIPLE: ANALYSIS AND CRITICISM OF THE PRINCIPLE OF SYMMETRY ACCORDING TO THE SENSE OF FEDERALISM IN BRAZIL}

Leonam Liziero $^{1}$

RESUMO: O presente artigo tem como objetivo expor argumentos que demonstram ser o princípio da simetria, utilizado como razão jurídica para motivar decisões do Supremo Tribunal Federal, mera panaceia para reafirmação do poderio da União. Será visto, para tanto, a distinção conceitual entre federalismo e federação e como tal distinção tem impacto direto na qualidade de simetria ou assimetria de um Estado federal. Verifica-se, em decisões de ADI desde 2014, a utilização do princípio da simetria e como este uso é inadequado de acordo com o sentido de federalismo no Brasil.

Palavras-chave: Federalismo; Princípio da Simetria; Federação; Assimetria Federativa; Supremo Tribunal Federal.

ABSTRACT: The purpose of this article is to present arguments that demonstrate the principle of symmetry, used as a legal reason to motivate decisions of the Federal Supreme Court, a mere panacea to reaffirm the power of the Union. The conceptual distinction between federalism and federation will be seen and as such a distinction has a direct impact on the quality of symmetry or asymmetry of a federal State. In ADI decisions since 2014, the use of the principle of symmetry is verified and how this use is inappropriate according to the sense of federalism in Brazil.

Keywords: Federalism; Principle of Symmetry; Federation; federal asymmetry; Brazilian Supreme Court.

INTRODUÇÃO

Esse artigo tem como objetivo expor as razões pelas quais o denominado princípio da simetria não se coaduna com o sentido de federalismo no Brasil. Para tanto, serão utilizados recursos

\footnotetext{
${ }^{1}$ Professor do Programa de Pós-Graduação em Ciências Jurídicas da Universidade Federal da Paraíba - UFPB. Doutor em Teoria e Filosofia do Direito pela UERJ com Pós-Doutorado em Direito pela UFRJ. Instituição: Universidade Federal da Paraíba - UFPB, Paraíba. Brasil. E-mail: leonamliziero@gmail.com
} 
da história constitucional brasileira, bem como argumentos de acordo com a contemporânea hermenêutica constitucional, para demonstrar que ao convalidar o princípio da simetria, os Ministros do Supremo Tribunal Federal utilizam-se de decisionismo com razões que não condizem com o federalismo brasileiro.

Para tal afirmação, é necessária a sustentação teórica baseada na distinção conceitual entre federalismo e federação. A partir de então, é possível demonstrar razões pelas quais a simetria não é possível no federalismo e, no caso do Brasil, em razão do elevado grau da assimetria federativa, seria mais coerente com seu sentido de federalismo que a federação brasileira se organizasse assimetricamente.

Em seguida serão analisados votos de Ministros do Supremo Tribunal Federal que utilizam o princípio da simetria como fundamento jurídico. O recorte temporal será dos últimos cinco anos, ou seja, a partir de 2014. Serão vistas as bases nas quais os Ministros se apoiam para decidir com base neste princípio e, desta forma, serão contraditas estas razões, demonstrando que não correspondem ao sentido de federalismo no Brasil e se tratam, no fundo, de justificativas meramente retóricas para afirmar um ato de vontade.

Por fim, discute-se o fascínio pelos princípios no Brasil, especialmente em seu uso para justificar decisões, em detrimento à motivação pelas regras. O princípio da simetria, conforme defendido, não é princípio jurídico: é, pois, um artifício utilizado em decisões do STF para a reafirmação do poderio da União no sistema federativo.

\section{FEDERALISMO E FEDERAÇÃO: UMA DISTINÇÃO CONCEITUAL NECESSÁRIA}

A distinção entre os conceitos de federalismo e federação se faz necessária por razões epistemológicas e repercutirá diretamente na compreensão do federalismo e federação como objetos de conhecimento que, embora relacionados, são diferentes. Para tanto, a distinção pode ser pensada a partir de um questionamento: a natureza do federalismo está no direito constitucional do Estado federal?

É preciso se estabelecer um parâmetro para o entendimento da natureza do federalismo. Conforme a proposta teórica de Livingston (1952), a natureza do federalismo está na sociedade e não no direito constitucional do Estado federal. Deste modo, o objeto de abordagem do federalismo como conceito amplia-se além do direito e, como consequência, distingue como objetos distintos, federalismo e Estado federal.

Livingston (1952, p. 85) designou como federalistas as sociedades nas quais as diferenciações sociais existentes, de natureza religiosa, étnica, econômica e histórica estão 
distribuídas territorialmente e nas quais cabe à política a tarefa de levar em conta a clivagem social e de assegurar a preservação daquelas sociedades.

Essas diversidades encontradas em grupos sociais (que podem ser diferenciados de outros) concentrados em uma mesma área geográfica, dentro de uma mesma sociedade, resultam no que Livingston entende ser a natureza do federalismo. A territorialidade é um fator determinante: "se estão agrupados territorialmente, que é geograficamente, então o resultado pode ser uma sociedade que é federal. Se eles não estão agrupados territorialmente, então a sociedade não pode ser federal" (LIVINGSTON, 1952, p. 83, tradução nossa). Deste modo, a sociedade será federal se for contiver diferentes grupos sociais que se identificam com algo em comum, formando uma sociedade maior e se estes grupos estiverem concentrados em áreas distintas.

Desse modo, uma sociedade pode ter instituições que são federais na aparência, mas que funcionam diferente, assim como ter uma estrutura unitária e funcionar federativamente. Há dissociação entre a forma do Estado e a práxis. Com estas premissas, Livingston propõe que o federalismo é um fenômeno sociológico. Assim, "a essência do federalismo não se encontra na estrutura institucional ou constitucional, mas na sociedade em si. O governo federal é um dispositivo pelo qual as qualidades federais da sociedade são articuladas e protegidas" (LIVINGSTON, 1952, p. 83, tradução nossa).

Seria possível mencionar inúmeros autores estrangeiros, como Burgess e Tarr, que apresentam distinções entre federalismo e federação. Todavia, para fins deste trabalho, será apresentado como esta distinção é vista teoricamente no Brasil sob o ponto de vista de autores brasileiros, como abaixo demonstrado, ainda que não sob influência da proposta de natureza do federalismo apresentada por Livingston.

Ao se estudar federalismo no Brasil, um dos autores mais relevantes é Raul Machado Horta. Em inúmeros artigos publicados sobre o tema, Horta deixa evidente a distinção conceitual entre federalismo e federação. Em um artigo nominado como Organização Constitucional do Federalismo, publicado em 1985, traz a discussão sobre a presença do federalismo na nova Constituição, em especial o equilíbrio na repartição de competências, que deveria tender à descentralização. Neste sentido, argumenta que o federalismo é um modelo constitucional, um valor que serve de inspiração para o Estado federal (HORTA, 1985, p. 14). Por sua vez, o Estado federal, segundo Horta $(1985$, p.6), "é criação jurídico-política e pressupõe na sua origem a existência da Constituição federal, para instituí-lo".

Também em outro autor de grande relevo para o estudo do federalismo no Brasil, José Alfredo de Oliveira Baracho, é encontrada esta distinção conceitual. Na obra de Baracho, o federalismo encontra diversas definições, mas sempre em um aspecto não formalista, que por sua 
vez motiva a estruturação do Estado federal. De acordo com este autor, "o federalismo é considerado como forma de distribuição de poder, tomado este em seu significado constitucional" (BARACHO, 1985, p. 53).

De acordo com Rosah Russomano (1968, p. 39), enquanto princípio de organização de poder, o federalismo "influenciou singularmente vários Estados, que o reconheceram de modo expresso, quase inelutável, porque ele, em verdade, envolve a forma estatal que reflete problemas inerentes ao próprio ser humano e que se simbolizam em seus anseios de unidade e diversidade". Por sua vez, na visão da autora, o Estado federal "seria a estrutura hábil para contemplar, harmonizando-se, aqueles problemas, já agora projetados, naturalmente, à órbita estatal e que se traduzem na unidade nacional e na diversidade regional" (RUSSOMANO, 1952, p. 39).

Nesse mesmo sentido, escreve Liziero $(2018$, p. 103) que o "federalismo é princípio reitor da forma de organização de Estado e a federação é a própria forma de organização de Estado em si". Ainda neste raciocínio, "um Estado federal é o resultado de um projeto político, seja com uma formação histórica e social com algum decurso temporal, seja em um ato único que modifica a forma de organização política" (LIZIERO, 2018, p. 103).

Uma vez feita esta análise conceitual da distinção entre federalismo e federação, é preciso verificar a assimetria como elemento na ideia revelada por estes conceitos. Deste modo, será possível pensar criticamente sobre a existência ou não de um princípio da simetria.

\section{A ASSIMETRIA NO SENTIDO DE FEDERALISMO BRASILEIRO}

Essa abordagem não-formalista do federalismo permite uma nova visão sobre o objeto como um fenômeno sociopolítico, que permite enxergá-lo como resultado da diversidade em précondições (BURGESS, 2006). Tais pré-condições estabelecem elementos assimétricos que caracterizam o federalismo como experiência histórica do federalismo enquanto ideal, no qual as unidades federativas deveriam ter fatores equivalentes. Neste raciocínio, a dicotomia entre a simetria e assimetria também se aplica ao Estado federal.

Conforme as conclusões de Liziero (2018, p. 183), baseada na distinção entre federalismo e federação, a noção de federalismo simétrico é utópica. Não há simetria no federalismo por ausência de experiência histórica com partes com características equivalentes. Deste modo, o federalismo, enquanto princípio de organização política, preexiste aos Estados federais e se mantém como diretriz para o comportamento das unidades da federação.

Em coadunação com a distinção conceitual entre federalismo e federação, pode-se pensar em momentos de formação do Estado federal. Assim, enquanto no momento do federalismo 
encontram-se pré-condições que permitem a formação do Estado federal, o Estado federal em si é o resultado do federalismo, formalizado a nível constitucional. A assimetria como elemento se manifesta tanto no âmbito do federalismo quanto da federação.

A assimetria no federalismo deve ser estudada conforme suas pré-condições, que no Brasil, segundo Liziero (2018, p. 113), podem ser condensadas em quatro: (i) diversidades culturais; (ii) territorialidade; (iii) desigualdades socioeconômicas; (iv) demografia. Deste modo, segundo o autor, estas pré-condições indicam a influência "que a assimetria terá na formação do Estado federal, uma vez que todos eles apresentam características assimétricas. Deste modo, a depender destas précondições, haverá maior ou menor influência na escolha da simetria ou assimetria de direito nos Estados federais".

O Estado brasileiro é marcado por elevadíssimo grau de assimetria nas pré-condições. Apesar não haver experiência histórica de federalismo com simetria em suas pré-condições, logo, o federalismo é, pois, assimétrico, em alguns Estados federais a assimetria em seu sistema federativo é justificável.

O Estado federal, enquanto resultado das pré-condições do federalismo, é caracterizado por assimetrias de fato e de direito. A assimetria de fato se refere à prática da assimetria nas relações que resultam do impacto das pré-condições, enquanto a assimetria de direito está relacionada ao ordenamento jurídico dos Estados e ao modo como as unidades federativas são tratadas diferentemente pela federação.

As assimetrias de direito, conforme Liziero (2018, p. 141-142), se manifestam no tratamento diferenciado no Senado (ou órgão equivalente) e na diferença da extensão das competências das unidades federativas, o que formará suas ordens jurídicas, ordens parciais dentro do Estado federal. É em relação a estas assimetrias de direito é que se pode dizer se uma federação é ou não assimétrica. Além disso, é possível que Estados federais simétricos tenham pequenas assimetrias em seu sistema sem que isso o caracterize como assimétrico, caso ele possua na ordem constitucional simetria no órgão de representação das unidades federativas e no direito dos Estados federados (ou qualquer que seja a denominação para o ente federativo).

É possível deduzir, ao se analisar as diversas Constituições dos Estados federais, que não há uma regra predominante dos Estados federais serem simétricos ou assimétricos. Federações como Canadá, Índia, Iraque, Alemanha, Bélgica, Rússia, por exemplo, possuem alguma manifestação de assimetria de direito. Em outras, como Estados Unidos, México, Argentina e Brasil, são estruturalmente simétricos.

O Brasil pode ser considerado como um Estado federal simétrico essencialmente por ter seu Senado composto por número iguais de representantes dos Estados e por todos os Estados terem 
as mesmas competências e serem estruturados aos moldes das instituições da União. Todavia, a despeito de ser uma federação simétrica, o Brasil apresenta um federalismo com altos índices de assimetrias em suas pré-condições, o que pode ser confirmado por uma investigação de sua história política e social.

O Estado federal brasileiro é centralizador (ARRETCHE, 2009), sendo que um dos fatores desta centralização é justamente sua simetria de direito. A centralização já presente no texto original da Constituição de 1988 (e maximizada pelas reformas dos anos 1990) se vincula à simetria, especialmente pela uniformização do direito e pelos poucos mecanismos de veto que os Estados possuem para se defender de decisões da União que os prejudiquem (como a Emenda Constitucional no3/1993, que incluiu o §4ㅇ no art. 167).

A assimetria do Estado federal no Brasil, por outro lado, pode ser um modo de descentralização. Segundo Liziero (2018, p. 187), "ao estabelecer o tratamento diferenciado a uma ou mais unidades, a Constituição descentraliza o sistema em relação àquelas que receberem mais competências". Além disso, a "descentralização ocorre também pela assimetria de direito na determinação de um Senado, ou órgão com equivalência funcional, com número de vagas diferentes para as unidades constitutivas" (LIZIERO, 2018, p. 187).

É possível questionar, com base nessas considerações, porque a descentralização é relevante para a questão da simetria ou assimetria no Brasil. A resposta se encontra na história constitucional brasileira, especialmente no sentido de federalismo por ela revelado. Em conformidade com as conclusões de Liziero, ao investigar a concepção de federalismo na Assembleia Nacional Constituinte de 1987/1988, o sentido é de um federalismo descentralizado e esperava-se a formação de um sistema federativo que conferisse aos Estados grande autonomia. De fato, pelo novo sistema de repartição de competências, fortemente inspirado pelas ideias de Raul Machado Horta, houve gradativa descentralização, mesmo assim a Constituição foi centralizadora (ARRETCHE, 2018, p. 380).

Assim, é possível inferir se a Constituição de 1988 não poderia ter sido descentralizadora se adotasse uma configuração assimétrica em sua repartição de competências ou no estabelecimento do Senado. Apesar da vontade dos Constituintes em ter um Estado federal descentralizado, de modo a acompanhar a descentralização no sentido de federalismo no Brasil, a Constituição de 1988 pode ter tido um resultado centralizador, entre outros fatores, por uma verdadeira atecnia na elaboração dos diversos Anteprojetos, desde as subcomissões temáticas até a o Projeto $\mathrm{D}$, por não ter se cogitado a assimetria de direito.

É importante deixar claro que não é porque o Estado federal no Brasil começou simétrico é que o federalismo acompanha esta simetria; ao contrário, se observa evidente assimetria no 
desenvolvimento do federalismo brasileiro, que se inicia muito antes da instauração da transformação do Brasil em Estado federal pelo Decreto nำ1, de 15 de novembro de 1889. Conforme demonstra a pesquisa de Miriam Dolhnikoff (2007, p.95), a época imperial foi marcada por forte embate federalista. Deste modo, independentemente de reconhecimento formal a nível constitucional, o federalismo pode estar presente na história política dos Estados. E isso reforça os argumentos da natureza sociopolítica do federalismo defendida por Livingston (1952, p. 95).

\section{PRINCÍPIO DA SIMETRIA E SEU USO NO STF COMO ARGUMENTO CENTRALIZADOR DA FEDERAÇÃO}

A partir do que foi apresentado, é possível pensar o federalismo brasileiro sob uma perspectiva sociológica e de sua história constitucional, de modo que estaria correto interpretar o sistema federativo com possibilidades assimétricas. Insurge-se esta visão à atual interpretação do Supremo Tribunal Federal, consagrado como princípio da simetria, como resultado de uma continuidade histórica de favorecimento à União em detrimento aos Estados.

Como Corte competente para resolver conflitos federativos, o Supremo Tribunal Federal foi instituído pelo Decreto no 510, de 22 de junho de 1890. Posteriormente, a Constituição de 1891 ratificou, em seu art. 59, I, "c", a competência para processar e julgar originaria e privativamente as causas e conflitos entre a União e Estados e conflitos entre Estados. Destaca-se que a criação do Supremo Tribunal Federal repercute diretamente na historicidade do federalismo e na estruturação do Estado federal brasileiro, "na medida em que a Corte teria sido diversas vezes acionada para dirimir conflitos federativos e demarcar 'territórios jurídicos' num país onde a diversidade de fontes de produção de atos normativos primários, coma consequente colisão entre elas, torna-se regra, e não exceção" (ARAÚJO, 2009, p. 58).

Conforme as conclusões de Lêda Boechat Rodrigues (1991), o Supremo Tribunal Federal tem, em suas decisões, tendência a defender a supremacia da União sobre os Estados. Deste modo, constata-se que o federalismo dual norte-americano não foi recebido pela prática jurisprudencial do órgão. Deste modo, a Constituição Federal tem sido aplicada integralmente em todos os Estados, de modo estabelecer um padrão de correção de inconstitucionalidades perpetradas pelos Estados.

O Supremo Tribunal Federal tende a atuar no sentido da uniformização as relações federativas, como defendem em teses de doutorado José Roberto Anselmo (2007) e Leonardo Paixão (2007). Para este último, a uniformização das instituições no Brasil é decorrente da jurisprudência centralizadora do Supremo Tribunal Federal. O Supremo Tribunal Federal também contribui para a centralização do Estado federal brasileiro com o julgamento de Ações Diretas de 
Inconstitucionalidade, cujas estatísticas demonstram grande tendência à declaração de leis estaduais como inconstitucionais (MARRAFON; LIZIERO, 2014).

A homogeneização do direito brasileiro por meio da atuação do Supremo Tribunal Federal com a consagração pela Corte do denominado princípio da simetria. É possível realizar a pesquisa, conforme o caminho metodológico indicado por Marcelo Labanca Corrêa de Araújo (2009, p. 77), de decisões do Supremo Tribunal Federal de Ações Diretas de Inconstitucionalidade propostas em face de leis estaduais e Constituições Estaduais, além da expressão "simetria".

O princípio da simetria encontra-se na fundamentação de votos de Ministros do Supremo Tribunal Federal, que direcionam para a centralização da prática federativa. Atualmente, o princípio da simetria é aplicado no sentido da uniformização das normas jurídicas, avançando-se inicialmente no processo legislativo estadual, que devem reproduzir as normas do processo legislativo federal, de modo a limitar a autonomia dos entes subnacionais. Também se observa a aplicação deste princípio da estruturação e atribuições do Poder Legislativo, Executivo e Judiciário dos Estados, além dos Tribunais de Contas.

É possível desta forma questionar, com fundamento na história constitucional brasileira, a utilização do princípio da simetria na interpretação do sistema federativo brasileiro. Lança-se a hipótese de que o posicionamento do Supremo Tribunal Federal colide com o sentido de federalismo, descentralizado e heterogêneo. Para tanto, faz-se necessária a concepção da natureza sociológica do federalismo, proposta por Livingston para pensa-la no Brasil a partir de uma leitura das instituições políticas.

Nesse raciocínio, mostra-se que a compreensão do federalismo brasileiro não se encontra limitada ao direito constitucional brasileiro, que por sua vez estrutura o Estado federal. Desta forma, a abordagem jurídica do federalismo é insuficiente, uma vez que não é capaz de demonstrar resultados para os problemas federativos ou mesmo demonstrar as razões das tensões entre as unidades federativas. Coaduna-se com a visão de Oliveira Vianna (1999), para quem o Brasil não se perfazia num continuum social e sim composto por uma sério de núcleos ou gânglios regionais, pela formação e estrutura social.

Nesse momento, passa-se à análise de como o denominado princípio da simetria é utilizado como recurso argumentativo pelo Supremo Tribunal Federal para reforçar sua posição centralizadora de manutenção de poder na União. Serão analisados alguns casos nos quais o princípio da simetria foi mencionado e serviu como razão jurídica para a motivação, não importando tanto assim o resultado do caso em si.

A obra de Araújo, publicada em 2009, analisa diversas utilizações do chamado princípio da simetria pelo STF, que servem para esclarecer como vem sendo usado. O que se busca aqui é analisar 
alguns casos nos quais o STF continuou utilizando tal princípio para motivar suas decisões. Para tanto, serão vistas decisões a partir de 2014.

Foram realizadas pesquisas no sítio eletrônico do Supremo Tribunal Federal (www.stf.jus.br), no campo "Jurisprudência > Pesquisa > Pesquisa de Jurisprudência". Foi digitada no espaço para a pesquisa livre o exato termo "princípio da simetria". A outra forma de especificação da pesquisa foi no campo "data", nos quais foram digitadas as datas de recorte de pesquisa de 10/01/2014 a $1 \% / 08 / 2018$.

Os resultados foram: 68 acórdãos, 776 decisões monocráticas, 20 decisões da presidência e 1 decisão de repercussão geral (O RE 1.059.466 Alagoas). Serão selecionados, dentre todos os acórdãos, para os propósitos deste artigo, seis deles, todos acerca de Ações Diretas de Inconstitucionalidade (ADI). Além destes seis casos, será também visto o uso do princípio da simetria nesta repercussão geral e como o termo é utilizado como mero ardil argumentativo.

Inicia-se com a análise da ADI 1.440 Santa Catarina (2014), de relatoria do Ministro Teori Zavascki, que resolveu um embate entre o Governador do Estado e a Assembleia Legislativa a respeito de reserva de inciativa legislativa. A lei contestada, Lei Estadual no 10.076/1996, estabelecia em seu art. $2 \circ$ que incorreria em crime de responsabilidade a autoridade que deixasse de cumprir o disposto em seu art. 1으, que suspendeu processos que tenham gerado punição a servidores estaduais civis e militares, em virtude de participação em movimentos de cunho reivindicatório ou manifestação de pensamento, de 1ㅇ de janeiro de 1991 até a data da publicação da lei.

O que se discutiu é se o Estado de Santa Catarina, por meio de lei infraconstitiucional, pode estabelecer conduta que tipifica crime de responsabilidade. A resposta do STF, ancorada no princípio da simetria, não foi outra senão declarar inconstitucional o art. 2o da citada lei, uma vez que Santa Catarina teria usurpado competência da União previstas nos arts. 22, I, e 85, parágrafo único, da Constituição Federal, bem como contrariou a Súmula 722 do STF.

Como bem evidente consta da ementa do acórdão, "não cabe a essas Casas Legislativas iniciar a deliberação de processos legislativos com esse objetivo, pois estão elas submetidas às normas processuais de reserva de iniciativa inscritas na Constituição Federal, por imposição do princípio da simetria". Veja-se a utilização do princípio da simetria neste voto.

Não entrando na discussão de mérito das razões de direito utilizadas para motivar o voto pela inconstitucionalidade a lei estadual catarinense, o Ministro Teori Zavascki não demonstrou em seu voto razões pelas quais menciona o princípio de simetria. Ele surge simplesmente como recurso argumentativo, sendo mencionado uma única vez, conforme descrito acima. Deste modo, guiado por tal princípio, e com a justificativa em outros dispositivos, o Ministro opta por decidir que o Estado 
de Santa Catarina não pode legislar sobre anistia a servidores e não pode estabelecer uma nova conduta acerca de crime de responsabilidade.

São inúmeras razões que podem justificar o dispositivo do voto de Teori Zavascki. O mencionado art. 22, I, da Constituição Federal seria o suficiente. Estabelece este inciso que apenas a União é competente para legislar sobre direito penal. Ao se considerar crime de responsabilidade como matéria de direito penal (é discutível, mas não será adentrado neste mérito), logo a Lei do Estado de Santa Catarina possui uma inconstitucionalidade evidente que seria esculpir uma nova conduta típica que culminasse num crime de responsabilidade.

A União no Brasil é demasiadamente centralizadora e um direito penal único como uniformização legislativa é uma dentre as inúmeras provas que demonstram esta centralização no sistema federativo. Todavia, o uso do princípio da simetria, sem menção alguma do porquê a federação brasileira deve ser interpretada simetricamente, reforça a comprovação da hipótese de que ele é utilizado como mero recurso argumentativo, como uma norma existente e que pode ser utilizada para motivar o ato de vontade do Ministro.

Em outra ocasião, na ADI 4792 Espírito Santo (2015), a Ministra Cármen Lúcia, relatora, teve igual posicionamento, ao entender que as legislações estaduais não podem definir hipóteses de crime de responsabilidade, uma vez que a Constituição Federal prescreve tal competência como privativa da União (art. 22, I).

Neste voto em especial, Cármen Lúcia menciona que:

O modelo de federalismo de equilíbrio adotado no Brasil acolhe o princípio da simetria, segundo o qual a principiologia harmoniza as estruturas e as regras que formam o sistema nacional e os sistemas estaduais, de modo a não desconstituir os modelos adotados no plano nacional e nos segmentos federados em suas linhas mestras.

Essa definição da Ministra é justificada por uma citação em seguida de um trecho de Direito Constitucional, de Raul Machado Horta. De fato, ao consultar a obra de Horta, encontra-se o trecho mencionado por Cármen Lúcia e utilizado para justificar o princípio da simetria. É o citado trecho:

A precedência da Constituição Federal sobre a do Estado-Membro é exigência lógica da organização federal, e essa precedência, que confere validez ao sistema federal, imprime a força de matriz originária ao constituinte federal e faz do constituinte estadual um segmento derivado daquele (HORTA, 2002, p. 69).

E continua a explicar o saudoso professor da UFMG:

A precedência lógico-jurídica do constituinte federal na organização originária da Federação torna a Constituição Federal a sede de normas centrais que vão conferir homogeneidade aos ordenamentos parciais constitutivos do Estado 
Federal, seja no plano constitucional, no domínio das Constituições Estaduais, seja na área subordinada da legislação ordinária (HORTA, 2002, p. 69).

Perceba-se que a citação utilizada pela Ministra não menciona nenhuma força obrigatória de um princípio da simetria para determinar que instituições estaduais sejam obrigadas exatamente a reproduzir as federais além do que é previsto na Constituição Federal. A homogeneidade a que Horta se refere certamente é em relação à uniformidade de legislação e os limites estabelecidos pela Constituição Federal às Constituições Estaduais, em conformidade com o que estabelece o art. 25. Deste modo, os Estados não devem ter legislação disforme àquilo que determina a Constituição em relação à repartição de competências. Isto não significa a revelação de um princípio da simetria.

Essa posição de Horta aqui mencionada pode ser comprovada pela publicação de um artigo específico sobre simetria e assimetria no federalismo, publicado na Revista do Tribunal de Contas do Estado de Minas Gerais, em 2002. Diz a respeito desta limitação:

A Constituição Federal de 1988 preservou o poder de auto-organização dos Estados, vinculado à elaboração da Constituição e das leis que adotarem e às competências reservadas, submetido seu exercício aos princípios da Constituição (art. $25, \S 1$ 으. . As regras do art. 25 e seu parágrafo 1 o consagram, explicitamente, a autonomia constitucional e a autonomia legislativa dos Estados e as submetem às limitações que dimanam da Constituição, no campo genérico de seus princípios (HORTA, 2002).

Neste mesmo artigo, ainda menciona Horta (2002) a respeito de uma possível simetria, menção na qual fica evidente que não defender qualquer princípio da simetria na federação brasileira: "a reunião das regras que se encontram disseminadas no texto da Constituição configurando princípios nela estabelecidos demonstra a extensão das limitações ao poder de autoorganização e a expansividade do federalismo assimétrico na Constituição Federal de 1988". Verificase assim que a citação de Horta utilizada por Cármen Lúcia para justificar um possível princípio da simetria não parece sustentável, especialmente por Horta não dizer isso.

Outra utilização do princípio se deu na ADI 3.077 Sergipe (2016), de relatoria da Ministra Cármen Lúcia, que resolveu questão acerca de competências do Tribunal de Contas sergipano, critérios de recondução do Procurador-Geral de Justiça daquele Estado, bem como escolha de superintendente de polícia civil.

Em relação ao Tribunal de Contas do Estado de Sergipe, a Constituição sergipana dispensava apresentação de parecer prévio sobre as contas de Chefe do Poder Executivo municipal a ser emitido pelo respectivo Tribunal de Contas Estadual, o que a Ministra considerou como inconstitucional. De acordo com suas razões, o art. 75 da Constituição Federal determina as normas constitucionais que regulamentam o Tribunal de Contas da União devem ser aplicadas aos Tribunais de Contas dos 
Estados e Municípios. Até este ponto, o argumento da Ministra mostra-se devidamente justificado. Todavia, em seu voto Cármen Lúcia menciona que: "a norma local não poderia excepcionar o que a Constituição da República não excepcionou, indo de encontro ao princípio da simetria expressamente previsto em seu art. 75, no concernente às competências precípuas dos Tribunais de Contas Estaduais". Este uso do princípio da simetria neste ponto é um pouco mais complexo do que aparenta.

Incialmente, precisa-se pensar porque o denominado princípio da simetria seria um princípio da federação brasileira. Esta é uma questão que será melhor detalhada no tópico seguinte. Mas de imediato, pode-se inferir que o princípio da simetria é uma proposição obtida por meio do estudo do sistema federativo do Brasil em razão de suas disposições constitucionais acerca da organização da federação. Não parece ser o princípio da simetria um princípio enquanto norma, uma vez que diferentemente do princípio da legalidade ou o princípio do juiz natural, não há elemento nele de essencialidade para a legitimação do sistema jurídico. Neste caso, ao contrário. Conforme demonstrado nos tópicos anteriores, se pela percepção apurada da história constitucional brasileira, uma norma-princípio que estabelecesse que os Estados devem reproduzir o que a União determina seria anacrônica.

Desse modo, é possível colocar em crise a afirmação de Cármen Lúcia de que o princípio da simetria estaria expressamente previsto no art. 75 da Constituição Federal. O que parece ser é uma regra de organização que tende à uma uniformização (já que a Federação brasileira é tendenciosamente centralizadora), mas que não chega a poder ser considerado como um princípio. O que fica evidente é o uso retórico para justificar o ato de vontade no voto.

Em outra passagem de seu voto, fazendo menção ao precedente da ADI 3.038 Santa Catarina (2014), a Ministra também justifica: "naquela assentada acompanhei o Relator para igualmente reafirmar a exigência de simetria entre os critérios da Constituição da República e das Constituições estaduais para a nomeação de chefes da Polícia Civil". É possível questionar o porquê.

Outro caso a ser destacado é a ADI 821 Rio Grande do Sul (2015), relatada pelo Ministro Gilmar Mendes, que discutiu a inconstitucionalidade da Lei Estadual no 9.726/1992 acerca da inciativa do Chefe do Poder Executivo estadual. Esta citada lei regulamentava os arts. 238 e 239 da Constituição rio-grandense. Em seu voto, o Ministro menciona: "a jurisprudência desta Corte, orientada pelo princípio da simetria, é firme em que cabe ao Governador do Estado a iniciativa de lei para criação, estruturação e atribuições de secretarias e de órgãos da administração pública". A decisão do Ministro foi declarar a inconstitucionalidade destes dois artigos da Constituição estadual e, por consequência, da Lei 9.726/1992. 
Novamente, não é o propósito aqui discutir se a decisão do Ministro foi acertada ou não, mas sim o uso do chamado princípio da simetria na decisão. Gilmar Mendes utiliza o princípio apenas para reverberar uma ideia por ele defendida no voto, sem citar fontes ou razões pelas quais exista um princípio da simetria. A questão pode ser resolvida com uma análise comparada das Constituições Federal e da rio-grandense.

A Constituição Federal em seu art. 61, §1으, alínea "a", determina que é de iniciativa reservada do Presidente da República projetos de lei para criação e extinção de Ministérios e órgãos da administração pública. Por sua vez, determina o art. 60, II, alínea "d", da Constituição do Estado do Rio Grande do Sul, que são de iniciativa privativa do Governador do Estado as leis que disponham sobre a criação, estruturação e atribuições das Secretarias e órgãos da administração pública do âmbito do Estado. Veja-se: não é a jurisprudência do STF ou o princípio da simetria que determinam a reserva da inciativa de tais leis ao Governador do Estado, mas sim a Constituição rio-grandense. É uma determinação do Poder Constituinte Derivado Decorrente que instituiu esta Constituição estadual em 3 de outubro de 1989.

Nada além do que é previsto a respeito do tema na Constituição Federal determina que os Estados devam seguir simetricamente a forma como as instituições federais se estabelecem. Nem ao menos é possível utilizar o art. 25 como justificativa para estabelecer tal força simétrica. Deste modo, se há correspondência entre a inciativa reservada das leis do Presidente da República e do Governador do Estado do Rio Grande do Sul, ela decorre da Constituição estadual antes mesmo de um "princípio da simetria" ou da jurisprudência do STF.

Mais uma utilização do princípio da simetria se percebe no voto do relator Ministro Gilmar Mendes na ADI 253 Mato Grosso (2015). Este caso discutia a inconstitucionalidade do art. 65 da Constituição mato-grossense, pedido que ao final foi julgado improcedente.

Ao iniciar seu voto, o Ministro começa o raciocínio sobre a limitação constitucional às ordens jurídicas estaduais pelo art. 25 da Constituição Federal e art. 11 do ADCT: "a necessidade de harmonia e homogeneidade, que se manifesta pelo princípio da simetria, não pode ser amarra absoluta às constituições estaduais". Com o que já foi exposto, é possível fazer uma crítica a esta afirmação de Gilmar Mendes: é correto dizer que a necessidade de harmonia e homogeneidade não pode ser uma amarra absoluta às Constituições dos Estados, mas isso não se dá em razão de um princípio da simetria. Aliás, não se mostra necessidade de homogeneidade além do que a repartição de competências da Constituição Federal determina. Assim, não é o princípio da simetria que prescrever uma homogeneidade; a homogeneidade existente é resultante do sistema de repartição de competências que se mostra altamente centralizador, logo, hipertrofiando a União (ARRETCHE, 
2009). Perceba-se no voto que o denominado princípio da simetria no voto do Ministro foi extraído especialmente da leitura dos art. 25 da Constituição, bem como do art. 11 do ADCT.

Outra utilização do princípio da simetria se encontra na ADI 3.564 Paraná (2014), relatada pelo Ministro Luiz Fux. Também se discutia a respeito de inciativa do Poder Executivo e no caso, foi declarada inconstitucional a Lei Estadual Complementar no 109/2005. Na leitura do art. 61, § 1으, II, "c" e do art. 84, III e VI, da Constituição Federal, somente Presidente da República pode ter a inciativa de leis que tratam sobre o regime dos servidores públicos da União.

Por um raciocínio de simetria, somente o Governador do Estado do Paraná teria também a reserva de inciativa para leis que disponham sobre regime dos servidores estaduais. Ao acompanhar o defendido no parecer do Procurador-Geral da República, expõe o Ministro: "é patente que a lei paranaense impugnada acaba por criar atribuições para órgão público integrante do Poder Executivo estadual, o que, pelo princípio da simetria, deveria decorrer de iniciativa do Governador do Estado". Luiz Fux fundamenta que o Governador deveria ter a inciativa reservada para dispor sobre a iniciativa para propor projetos de lei que visem à criação, estruturação e à delimitação de atribuições de Secretarias e órgãos da Administração Pública estadual em razão do princípio da simetria.

Não é o princípio da simetria o fundamento mais correto para a inconstitucionalidade da citada lei complementar. A leitura do art. 66, II, da Constituição paranaense, deixa evidente que se há um vício de iniciativa, ele é decorrente desta determinação. Esta norma prescreve ser de inciativa privativa do Governador do Paraná as leis que disponham sobre servidores públicos do Poder Executivo. Perceba-se, tendo o trecho do voto de Luiz Fux mencionado acima, que a iniciativa reservada do Governador do Estado não decorre do princípio da simetria, mas sim da Constituição do Estado do Paraná. A simetria foi uma opção do Constituinte derivado decorrente; não é um valor revelado pela leitura da Constituição Federal.

Como outra manifestação da polissemia do termo, por fim, o uso do termo "princípio da simetria" ganha outro "significado" no Recurso Extraordinário 1.059.466 RG/AL, cuja repercussão geral da matéria foi reconhecida, em conformidade com o art. 1035 do CPC. Este é um excelente caso que demonstra limpidamente a hipótese levantada neste artigo, de que o dito "princípio da simetria" não é princípio jurídico. Neste Recuso Extraordinário, utilizou-se o termo para fundamentar algo que não necessariamente tem a ver com uma questão federativa.

O RE 1.059.466 RG/AL, de relatoria do Ministro Alexandre de Moraes, tratou de resolver uma questão de equiparação de carreiras da magistratura e do Ministério Público acerca da percepção de licença-prêmio (ou indenização pela sua não-fruição) de juízes federais. Neste caso, uma magistrada (a autora da ação) solicitava direito à licença-prêmio igual à prevista na Lei 
Complementar no 75/1993 (Lei Orgânica do Ministério Público) em seu art. 222, III. O relator votou pela improcedência.

O que chama a atenção neste caso, para os propósitos deste artigo, é a utilização do termo princípio da simetria para a defesa de um ponto de vista em uma discussão que não é de cunho federativo. Neste Recurso Extraordinário, o uso do termo se perfaz em uma significação de equivalência.

Assim, ao fundamentar suas decisões com o princípio da simetria, enquanto argumento jurídico, o STF atua como agente centralizador da Federação brasileira, pois além de prezar pela uniformização entre unidades federativas com realidades visivelmente díspares, desprestigia o Poder Constituinte Derivado Decorrente, que faz determinações e escolhas, dentro dos limites expressos pela Constituição Federal. Desta forma, antes de apresentar um argumento baseado em um suposto princípio da simetria, como se fosse um valor presente na norma constitucional federal, é preciso apreciar as determinações das Constituições estaduais.

\section{“PRINCÍPIO DA SIMETRIA" COMO PANACEIA}

Conforme demonstrado, o uso do princípio da simetria pelo STF tem propósito retórico e o efeito de reafirmar a hipertrofia da União, na já tão centralizada Federação brasileira. O que se pretende expor agora são algumas razões pelas quais o princípio da simetria é apenas mais um dos princípios que surgiram com o movimento panprincipiológico no Brasil e que seu uso em decisões consolida o poderio da União, o que de certo modo contraria o sentido de federalismo, relacionado à descentralização, na história constitucional contemporânea brasileira.

Marcelo Neves faz imprescindível crítica ao uso e abuso dos princípios na prática jurídicoconstitucional brasileira no capítulo final de Entre Hidra e Hércules. Suas considerações servirão de referencial teórico para a crítica feita neste trabalho ao uso do princípio da simetria. Segundo Neves (2013, p. 171), este fascínio na doutrina constitucional brasileira e, consequentemente, na prática jurisprudencial, é "uma atitude que, com destacada exceções, tem contribuído para uma banalização das questões complexas referentes à relação entre princípios e regras".

Em sua crítica ao principialismo no Brasil, por razões entre as quais a recepção inadequada de teorias estrangeiras e a inconsistência na produção do direito, Neves (2013) identifica que se existe na prática jurídica inconsistência, a reflexão jurídica, tanto da dogmática jurídica quanto da teoria do direito, fica fragilizada. A partir de então, abrem-se duas alternativas: (a) a retroalimentação da prática inconsistente, que é sujeita a pressões de particularismo sociais; ou (b) o oferecimento de um aparato teórico sólido para poder transformar a prática jurídica. A crítica neste 
trabalho feita ao princípio da simetria se refere à prática inconsistente do Supremo Tribunal Federal, que atua como um agente da centralização da Federação brasileira.

Na divisão normativa entre princípios e regras, Neves observa que a prática inconsistente tem tendência a rejeitar as regras em razão de sua definitividade. Por sua vez, os princípios são estruturas de reflexão que não alcançam razões definitivas em si. Os princípios, deste modo, "podem mais facilmente ser articulados para encobrir soluções que minam a consistência da ordem jurídica a favor de interesses particularistas que pressionam a solução do caso" (NEVES, 2013, p. 190).

O Brasil, com algumas das afirmações propagadas com o chamado neoconstitucionalismo, sofre desta desdita. Os princípios fascinam o estudioso do direito, bem como aplicador do direito (como os juízes), de tal maneira que há uma sugestão de superioridade intrínseca dos princípios em relação às regras (NEVES, 2013, p. 191). Assim, tem-se uma completa deturpação de teorias estrangeiras, como as de Dworkin (em Levando os Diretos a Sério e O Império do Direito), Müller (Metódica Jurídica e Sistema Político) e Alexy (Teoria da Argumentação Jurídica), muito difundidas no Brasil. Tal deturpação serve de pretexto para a motivação na interpretação do direito, segundo a qual seria possível deixar de aplicar regras em favor de princípios.

Neves (2013, p. 191) deixa evidente o que significa o afastamento de regras em razão da invocação de princípios em nome da justiça: "em uma sociedade complexa com várias leituras possíveis dos princípios, serve antes à acomodação de interesses concretos e particulares, em detrimento à força normativa da Constituição". Assim, neste raciocínio, o uso de princípios para motivar decisões ou justificar determinado ponto de vista quando é possível aplicar regras, ou quando estas não são consideradas, mostra-se nocivo tanto para a prática jurídica quanto para a teoria do direito no Brasil.

No sentido moderno, a Constituição é o acoplamento estrutural entre a política e o direito. Assim, mediante a Constituição se relacionam reciprocamente democracia e Estado de Direito (NEVES, 2013, p. 195). O uso desmedido de ponderação de princípios no Brasil, observa-se uma irracionalidade tanto para o sistema político (democracia) quanto para o sistema jurídico (Estado de Direito).

Chama-se a atenção para esta função da Constituição destacada por Neves. Por ser um Estado federal, a Constituição Federal brasileira é o ápice de todo o ordenamento jurídico nacional, seja a ordem federal, sejam as ordens estaduais e municipais. É da Constituição Federal que é retirada tanto a validade para as normas infraconstitucionais federais, quanto para as Constituições estaduais, que são a manifestação expressa do Poder Constituinte Derivado Decorrente. Assim como a Constituição Federal e dentro de suas diretrizes, as Constituições estaduais também acoplam direito e política no nível dos Estados federados. 
A prática deste principialismo no Brasil é prejudicial não apenas para a Constituição Federal, mas também para as Constituições estaduais, uma vez que também há enfraquecimento da força normativa destas. Apesar do art. 25 da Constituição de 1988 determinar que, observados seus princípios, os Estados devem se organizar pelas Constituições que adotarem, o que se verifica é que as Constituições estaduais em grande parte de seus textos reproduzem o que é disposto na Federal.

Nesse sentido, observa Celina Souza (2005, p. 111) que "as poucas tentativas de criar regras não explicitamente especificadas pela Constituição federal, mas não proibidas, foram declaradas inconstitucionais pelo STF". Como visto no tópico anterior, muitas vezes o STF utiliza o princípio da simetria como motivação para declarar inconstitucional normas no âmbito estadual. E a hipótese aqui defendida é que o uso deste princípio na prática do STF, sem solidez teórica em se buscar os fundamentos do federalismo, é que há o inevitável enfraquecimento da normatividade das Constituições estaduais, da Constituição Federal e do sistema federativo como um todo. Assim, o princípio da simetria se perfaz como mais um entre os tantos princípios criados pelo fascínio principialista no Brasil, conforme a crítica de Neves, para justificar interesses, que no caso é a reafirmação constante do poderio da União.

Então, no que consiste este suposto princípio (que na hipótese aqui formulada não é consistentemente um princípio jurídico)? Sergio Ferrari busca responder esta questão ao analisar a jurisprudência do STF em relação às Constituições estaduais. Segundo este autor, este suposto princípio foi elaborado e enunciado pela linha jurisprudencial do STF. Ferrari questiona também sua natureza, já que utiliza o termo princípio entre aspas ao defini-lo. Assim, segundo suas palavras, "por este 'princípio', a norma da constituição estadual que não se repete, para o Estado-membro, a fórmula da Constituição Federal para a União, seria inconstitucional” (2003, p. 194).

De modo mais amplo, Araújo (2009, p. 125) observa que o princípio da simetria "também é utilizado para legitimar a atividade constituinte ou legislativa ordinária do estado-membro sem que haja um mandamento obrigatório". Desta forma, "o princípio da simetria é utilizado como critério argumentativo em face de normas constitucionais federais que devem, que podem e que não podem ser reproduzidas perante as Constituições estaduais" (2009, p. 125). Neste raciocínio, para Araújo, o princípio da simetria é um princípio de interpretação e não um princípio jurídico.

Conforme aqui defendido, o princípio da simetria não é um princípio jurídico em si. Trata-se de uma invocação retórica, uma panaceia para a solução de problemas constitucionais no Brasil, com base nas observações feitas por Neves (2013, p. 196). Não é possível nem ao menos argumentar que este suposto princípio incorpora valores ao sistema jurídico. Conforme também demonstra Neves (2013, p. 41), não é possível distinguir um princípio constitucional de uma regra em razão de caráter teleológico ou valorativo. A distinção entre princípios e regras constitucionais, neste sentido, surge 
no plano argumentativo. Todavia, não se pode confundir com prática irracionalista do fascínio pelo principialismo no Brasil. Assim, o chamado princípio da simetria, que não é princípio jurídico, é apenas mais uma manifestação deste abuso do uso retórico dos princípios, de modo a enfraquecer a normatividade constitucional e o sistema federativo brasileiro.

\section{CONCLUSÕES}

O federalismo pode ser visto sob uma abordagem sociológica que permite a distinção entre federalismo e federação e a análise de pré-condições assimétricas que podem gerar um Estado federal assimétrico. Ainda assim no Brasil, observa-se uma discrepância em razão das assimetrias do federalismo não repercutirem nas estruturas simétricas do Estado federal.

A partir de uma leitura da Constituinte de 1987/1988, revela-se que no Brasil o sentido de federalismo tende à descentralização, que foi o discurso dominante naquela ocasião. Todavia, em contraste, historicamente a organização federativa do Estado assumiu um alto grau de centralização de poder na União, em movimento pendular a depender da Constituição em vigor, mas ainda assim, caracteristicamente centralizada. Em 1988, apesar do discurso quase que uníssono pela descentralização, o resultado foi uma Constituição centralizadora, tanto pela grande gama de competências da União, quanto pelos poucos mecanismos de veto que os entes subnacionais possuem.

Uma das formas de demonstrar como a descentralização está no sentido de federalismo brasileiro é analisar seu grau de assimetria. O federalismo é por si assimétrico; algumas manifestações de federalismo com grau de assimetria maior do que outros. No Brasil se observa elevadíssimo grau, o que também contrasta com o modelo simétrico da federação imposto desde a Proclamação da República.

A centralização da Federação brasileira encontra no STF um agente na prática jurídica. Assim, o STF, ao se utilizar de um recurso retórico que os Ministros denominam em seus votos como princípio da simetria, retroalimenta a centralização do Estado federal brasileiro. O princípio da simetria, conforme demonstrado, não é um princípio jurídico; é um recurso argumentativo de cerceamento da autonomia dos Estados federados, em especial das disposições de suas Constituições.

A uniformização normativa no Estado federal brasileiro além do que dispõe a Constituição Federal nos poderes enumerados da União, fundamentada num suposto princípio da simetria, contribui para a corrosão do já fragilizado sistema federativo brasileiro, além da inconsistência da 
prática jurídica no Brasil, com o fenômeno do fascínio pelos princípios dos aplicadores e estudiosos do direito.

\section{REFERÊNCIAS}

ANSELMO, José Roberto. O papel do Supremo Tribunal Federal na concretização do federalismo brasileiro. Tese (doutorado), Faculdade de Direito, Pontifícia Universidade Católica de São Paulo, São Paulo, 2007.

ARAÚJO, Marcelo Labanca Corrêa de. Jurisdição Constitucional e Federação: O princípio da simetria na jurisprudência do STF. Rio de Janeiro: Elsevier, 2009.

ARRETCHE, Marta. Continuidades e Descontinuidades da Federação Brasileira: De como 1988 facilitou 1995. Dados - Revista de Ciências Sociais, Rio de Janeiro, vol. 52, no 2, pp. 377-423, 2009.

BARACHO, José Alfredo de Oliveira. Teoria Geral do Federalismo. Belo Horizonte: Fumarc/UFMG, 1982.

BURGESS, Michael. Comparative Federalism: Theory and Practice. London: Routledge, 2006.

DOLHNIKOFF, Miriam. O pacto imperial: origens do federalismo no Brasil. São Paulo: Globo, 2007.

HORTA, Raul Machado. As novas tendências do federalismo e seus reflexos na Constituição brasileira de 1988. Revista do Legislativo, ALMG, no 25, pp.14-25, 1999.

. Direito Constitucional. 3.ed. Belo Horizonte: Del Rey, 2002.

Formas Simétrica e Assimétrica do Federalismo no Estado Moderno. Revista do Tribunal de Contas do Estado de Minas Gerais. n.2, 2002. Disponível em < http://200.198.41.151:8081/tribunal_contas/1998/01/02/2002_11_11_0003.2xt/\%ADversao_impr essao?ed=02\&folder=2>. Acesso em 25 de jan. 2017.

p.5-22, 1985

Organização constitucional do federalismo. Revista de Informação Legislativa, a.22 n. 87,

LIVINGSTON, William S. A Note on the Nature of Federalism. Political Science Quarterly, Vol. 67, No. 1, pp. 81-95, 1952.

LIZIERO, Leonam Baesso da Silva. Estado Federal no Brasil: o federalismo na Constituinte de 1987/1988 e a descentralização pela assimetria. Florianópolis: Empório Modara, 2018.

MARRAFON, Marco Aurélio; LIZIERO, Leonam Baesso da Silva. Competências constitucionais da União e Supremo Tribunal Federal: fiadores da centralização no federalismo brasileiro. In: FISCHER, Octavio Campos. Federalismo Fiscal e Democracia. Curitiba: Instituto Memória, 2014.

NEVES, Marcelo. Entre Hidra e Hércules: Princípios e Regras Constitucionais. São Paulo: Martins Fontes, 2013. 
OLIVEIRA VIANNA, Francisco José de. Instituições Políticas Brasileiras. Brasília: Conselho Editorial do Senado Federal, 1999.

PAIXÃO, Leonardo André. A Função Política do Supremo Tribunal Federal. 2007. 258p. Tese (doutorado), Faculdade de Direito, Universidade de São Paulo, São Paulo, 2007.

RODRIGUES, Lêda Boechat. História do Supremo Tribunal Federal. São Paulo: Record, 1991.

RUSSOMANO, Rosah. Lições de Direito Constitucional. Rio de Janeiro: José Kofino Editor, 1968.

SOUZA, Celina. Federalismo, desenho constitucional e instituições federativas no Brasil pós-1988. Revista de Sociologia e Política, n. 24, p. 105-122, 2005.

Trabalho enviado em 08 de dezembro de 2018

Aceito em 05 de fevereiro de 2019 